\title{
AVALIAÇÃO TEMPORAL E ESPACIAL DA REDE DE CIDADES DE MINAS GERAIS NO PERÍODO DE 1960 A 1991
}

\author{
Aílton Mota de Carvalho (*) \& Frederico Niffinegger Barbi (**)
}

\begin{abstract}
The paper describes and analyses the evolution in time and space, of the urban network of the State of Minas Gerais, between 1960 e 1991, focusing on its distribution by city-size, and on the dynamics of regional space.
\end{abstract}

\section{INTRODUÇÃO}

A urbanização, representada por uma parcela cada vez maior de população vivendo nas cidades, é um fato incontestável e que caracteriza todos os países. Nos países do terceiro mundo, especialmente, o aumento de população se fez num ritmo muito acelerado, provocando um aumento significativo do número e do tamanho das cidades.

O Brasil, naturalmente, apresentou o mesmo comportamento, caracterizando-se por expressivos índices de crescimento da população urbana. Entre 1940 e 1970, a população urbana cresceu 4,1 vezes, passando de 12,9 para 52,9 milhões de pessoas e no intervalo de 1970 a 1991, a população praticamente dobrou, ao atingir cerca de 111 milhões de pessoas.

Em Minas Gerais, o processo de urbanização também se deu de uma maneira rápida, especialmente nas três últimas décadas, quando o Estado deixou de ser uma região predominantemente rural. No Censo Demográfico de 1970, a população urbana ultrapassou a população rural, pela primeira vez. $O$ índice de urbanização do Estado passou de 39,6\% em 1960, para $67,1 \%$ em 1980 e para $74,9 \%$ em 1991 . O crescimento do índice entre 1960/1970 foi de 33,0\%; entre 1970/ 1980 foi de $27,3 \%$ e entre $1980 / 1991$ caiu para $11,6 \%$; demonstrando uma tendência constante da diminuição do ritmo de urbanização.

Este incremento de população urbana não ocorreu de uma forma homogênea no espaço mineiro, privilegiando algumas regiões e resultando numa maior concentração demográfica nestas áreas.

Quando analisamos a distribuição de população urbana por cidades e segundo faixas de tamanho de população, observamos que a repartição é também desigual. Nos quatro momentos estudados, 1960, 1970, 1980 e 1991, o que se observa é um pequeno número de cidades concentrando a maior parte da população urbana. Em 1960, 6,2\% do número de cidades concentravam 50,3\% da população urbana; em 1970,
6,4\% do número total de cidades concentravam 58,3\% da população urbana, em 1980, 9,6\% das cidades concentravam 66,6\% da população urbana e em 1991 $12,3 \%$ das cidades concentravam $69,6 \%$ da população urbana total.

Julgamos importante entender a dinâmica e a tendência do processo mineiro de urbanização como forma de recolher elementos que permitam uma prática mais eficaz do planejamento urbano e regional.

Portanto, o objeto desse estudo é analisar a evolução urbana mineira por tamanho de cidades e sua distribuição e dinâmica regional, no período de 1960 a $1991^{1}$.

\section{DINÂMICA DA POPULAÇÃO TOTAL, URBANA E RURAL}

\section{POPULAÇÃO TOTAL}

A evolução do crescimento da população total do Estado se manteve mais ou menos uniforme entre 1960 e 1991. Em 1960 a população era de 9.812.352 habitantes e em 1991 passou para 15.702.594 habitantes, correspondendo a um acréscimo absoluto de 5.890.242 pessoas, ou seja, um crescimento de $60 \%$ no período de 30 anos (Quadro 1 e Gráfico 1).

Na década 1960/1970, o aumento absoluto de população foi de ordem de 1.675 .063 habitantes, enquanto que o aumento verificado na década 1970/ 1980 foi de 1.903 .490 habitantes. Já na década de 1980/ 1991, o aumento ocorrido foi de 2.311 .789 habitantes, o maior entre as três décadas.

Apesar do aumento absoluto verificado, a taxa de crescimento experimentou uma leve diminuição, caindo de $17,1 \%$ na década $1960 / 1970$ para $16,6 \%$ entre 1970 / 1980 e voltando a subir no decênio de 1980/1991 para 17,3\% (Quadro 2).

Em termos regionais o confronto das taxas de crescimento nas três décadas analisadas apresenta uma grande variação. Na Região I, a taxa de crescimento

1 - Registramos que por razões metodológicas, este estudo adotou a divisão do Estado de Minas Gerais em 8 (oito) Regiões de Planejamento, conforme nos mostra o cartograma I. 


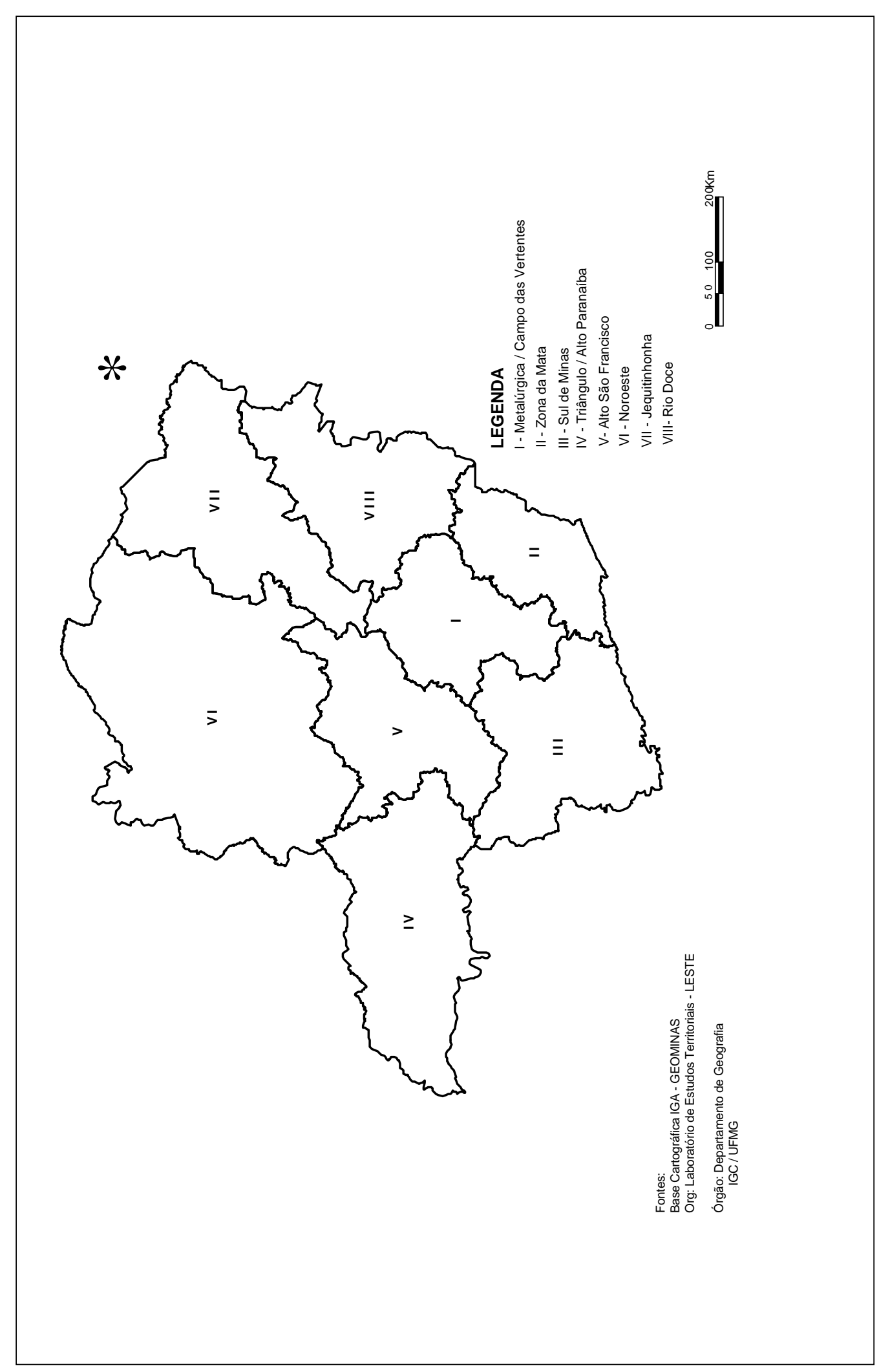


vem diminuindo com o passar das décadas, contrastando com as Regiões II e III que obtiveram um crescimento positivo durante todo o período estudado. As demais regiões tiveram oscilações em suas taxas de crescimento (retomaram o crescimento ou diminuíram o mesmo) durante os três decênios.

Estas variações permitem supor uma reorientação da distribuição de população dentro do território mineiro.

Em termos individuais, a Região VIII (Rio Doce) obteve o crescimento mais expressivo durante as duas últimas décadas, passando de uma taxa negativa de $-10,7 \%$ na década de $1970 / 1980$ para uma taxa de $0,3 \%$ na década de 1980/1991.

A Região I (Metalúrgica) teve seu índice total de crescimento bastante diminuído, de $51,9 \%$ para $44 \%$ entre o período de 1960 e 1980, decaindo posteriormente para 26,7\% na década de 1980/1991. É bomlembrar que essa região é a de maior população e crescimento absoluto.

\begin{tabular}{|c|c|c|c|c|c|c|c|c|c|c|c|c|}
\hline \multirow[t]{2}{*}{ REGIÃO } & \multicolumn{3}{|c|}{1960} & \multicolumn{3}{|c|}{1970} & \multicolumn{3}{|c|}{1980} & \multicolumn{3}{|c|}{1991} \\
\hline & total & urbana & rural & total & urbana & rural & total & urbana & rural & total & urbana & rural \\
\hline I & $\begin{array}{c}196795 \\
2\end{array}$ & 1295851 & 672101 & 2988590 & 2537893 & 630697 & 4303865 & 3766689 & 537176 & 5454495 & 4890562 & 563933 \\
\hline II & $\begin{array}{c}153478 \\
6\end{array}$ & 562937 & 971849 & 1579707 & 778296 & 801411 & 1644512 & 996387 & 648125 & 1843881 & 1276529 & 567352 \\
\hline III & $\begin{array}{c}175297 \\
6\end{array}$ & 702289 & 1050687 & 1836632 & 934130 & 902502 & 2082314 & 1036136 & 776178 & 2409230 & 1726434 & 682796 \\
\hline IV & 730732 & 355637 & 375095 & 915184 & 550383 & 364801 & 1155365 & 904188 & 251177 & 1396121 & 1187663 & 208458 \\
\hline V & 627210 & 229622 & 397588 & 647803 & 320209 & 327594 & 661001 & 428707 & 232294 & 737399 & 558083 & 179316 \\
\hline $\mathrm{VI}$ & 803237 & 170419 & 632818 & 1013393 & 302472 & 710921 & 1193602 & 555245 & 638357 & 1430827 & 848926 & 581901 \\
\hline VII & 693643 & 139932 & 553711 & 798616 & 205117 & 593499 & 825412 & 284408 & 541004 & 901341 & 401330 & 500011 \\
\hline VIII & 170181 & 429799 & 1272017 & 1707490 & 611800 & 1095690 & 1524734 & 744506 & 780228 & 1529300 & 881454 & 647846 \\
\hline $\begin{array}{l}\text { Minas } \\
\text { Gerais }\end{array}$ & $\begin{array}{c}981235 \\
2\end{array}$ & 3886486 & 5925866 & 11487415 & 6060300 & 5427115 & 13390805 & 8986266 & 4404539 & 15702594 & 11770981 & 3931613 \\
\hline
\end{tabular}

Chart 1: Evolution of population in Minas Gerais- total, urban and rural.

\begin{tabular}{|c|c|c|c|c|c|c|c|c|c|c|c|c|c|c|c|c|c|c|}
\hline \multicolumn{7}{|c|}{ VARIAÇÃO 1960/1970 } & \multicolumn{6}{|c|}{ VARIAÇĀO 1970/1980 } & \multicolumn{6}{|c|}{ VARIAÇĀO 1980/1991 } \\
\hline RE- & \multicolumn{2}{|c|}{ to tal } & \multicolumn{2}{|c|}{ urbana } & \multicolumn{2}{|c|}{ rural } & \multicolumn{2}{|c|}{ to tal } & \multicolumn{2}{|c|}{ urbana } & \multicolumn{2}{|c|}{ rural } & \multicolumn{2}{|c|}{ to tal } & \multicolumn{2}{|c|}{ urbana } & \multicolumn{2}{|c|}{ rural } \\
\hline GIÃO & abs. & $\%$ & abs. & $\%$ & abs. & $\%$ & abs. & $\%$ & abs. & $\%$ & abs. & $\%$ & abs. & $\%$ & abs. & $\%$ & abs. & $\%$ \\
\hline I & $1 E+06$ & 51,9 & $1 \mathrm{E}+06$ & 82 & -41404 & -6 & $1 E+06$ & 44 & $1 \mathrm{E}+06$ & 60 & -93521 & -15 & $1 E+06$ & 26,7 & $1,1 \mathrm{E}+07$ & 29,8 & 26757 & 5 \\
\hline II & 44921 & 2,9 & 215359 & 38 & $-2 E+05$ & -18 & 64805 & 4,1 & 218091 & 28 & $-2 E+05$ & -19 & 199369 & 12,1 & 280142 & 36 & -80773 & -13 \\
\hline III & 83656 & 4,8 & 231841 & 33 & $-1 E+05$ & -14 & 245682 & 13 & 372006 & 40 & $-1 E+05$ & -14 & 326916 & 15,7 & 420296 & 45 & -93380 & -12 \\
\hline IV & 184452 & 25,2 & 194746 & 55 & -10294 & -3 & 240175 & 26 & 353805 & 64 & $-1 E+05$ & -31 & 240756 & 2,8 & 283475 & 51,5 & -42719 & -17 \\
\hline $\mathrm{V}$ & 20593 & 3,3 & 90587 & 40 & -69994 & -18 & 13198 & 2 & 108498 & 34 & -95300 & -29 & 76398 & 11,5 & 129376 & 40,4 & -52978 & 23 \\
\hline VI & 210156 & 26,2 & 132053 & 78 & 78103 & 12 & 180209 & 18 & 252773 & 84 & -72564 & -10 & 237225 & 19,9 & 293681 & 97,1 & -56456 & $-8,8$ \\
\hline VII & 104973 & 15,1 & 65185 & 47 & 39788 & 7,2 & 26796 & 3,4 & 79291 & 39 & -52495 & $-8,8$ & 75929 & 9,2 & 116922 & 41,1 & -40993 & $-7,6$ \\
\hline VIII & 5674 & 0,3 & 182001 & 42 & $-2 E+05$ & -14 & $-2 E+05$ & -11 & 132706 & 22 & $-3 E+05$ & -29 & 4566 & 0,3 & 136948 & 18,4 & $-1 E+05$ & -17 \\
\hline \multicolumn{19}{|l|}{ Minas } \\
\hline Gerais & $2 \mathrm{E}+06$ & 17,1 & $2 E+06$ & 56 & $-5 E+05$ & -8 & $2 \mathrm{E}+06$ & 17 & $3 E+06$ & 48 & $-2 E+06$ & -19 & $2 \mathrm{E}+06$ & 17,3 & 2784715 & 31 & $-4 E+05$ & -11 \\
\hline
\end{tabular}

Chart 2: Variation of population - total, urban and rural.

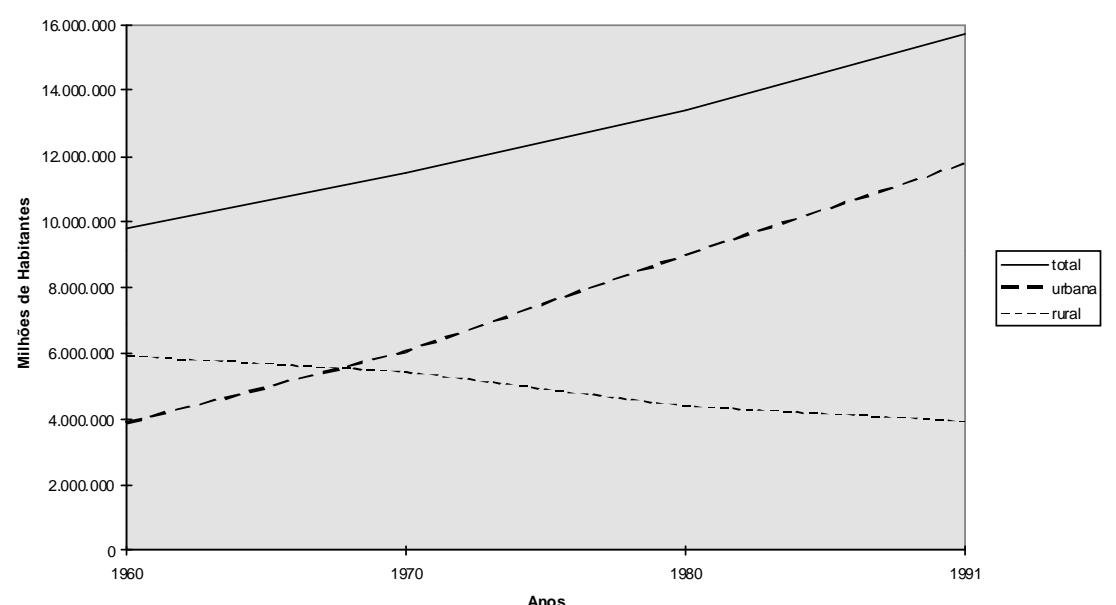

Gráfico 1: Evolução da população do Estado de Minas Gerais - total, urbana e rural.

Graphic 1: Evolution of population of Minas Gerais State - total, urban and rural. 


\section{POPULAÇÃO URBANA}

A população urbana, no período analisado, se caracterizou por seus elevados índices de crescimento absoluto e relativo. Entre 1960 e 1991, a população urbana de Minas Gerais cresceu de 3,8 milhões para 11,7 milhões, ou seja, 3 vezes mais.

Na década de 1960/1970, o aumento relativo foi o maior, dentro do período analisado, com uma taxa de $55,9 \%$, enquanto que nas décadas subsequentes o índice de crescimento da população urbana decaiu para 48,3\% e depois para 31\% (Quadro 3), (Gráficos 2 a 5).
O comportamento regional foi heterogêneo, uma vez que as Regiões III, V e VI tiveram maior índice de crescimento de população urbana entre as três décadas estudadas, enquanto que as Regiões I, II, IV, VII e VIII apresentaram um decréscimo no índice de 1980/1991, em relação à variação ocorrida entre 1960/1970. A Região I (Metalúrgica), apesar de ainda manter a primazia da concentração de população urbana do Estado (41,6\% em 1991), experimentou uma diminuição significativa no seu índice de crescimento que passou de $82 \%$ no período 1960/1970 para 59,7\% entre 1970/1980 e 29,8\% na última década.

\begin{tabular}{|c|c|c|c|c|c|c|c|c|c|c|c|c|}
\hline \multirow{2}{*}{ REGIÃO } & \multicolumn{3}{|c|}{1960} & \multicolumn{3}{|c|}{1970} & \multicolumn{3}{|c|}{1980} & \multicolumn{3}{|c|}{1991} \\
\hline & total & urbano & rural & total & urbano & rural & total & urbano & rural & total & urbano & rural \\
\hline I & 20,1 & 33,2 & 11,3 & 26,0 & 38,9 & 11,6 & 32,1 & 42,0 & 12,2 & 34,8 & 41,6 & 14,3 \\
\hline II & 15,6 & 14,5 & 16,4 & 13,8 & 12,8 & 14,9 & 12,3 & 11,1 & 14,7 & 11,7 & 10,8 & 14,4 \\
\hline III & 17,9 & 18,1 & 17,7 & 16,0 & 15,4 & 16,6 & 15,5 & 14,5 & 17,6 & 15,4 & 14,7 & 17,5 \\
\hline IV & 7,4 & 9,2 & 6,3 & 8,0 & 9,1 & 6,7 & 8,6 & 10,0 & 5,7 & 8,9 & 10,1 & 5,3 \\
\hline V & 6,4 & 5,9 & 6,7 & 5,6 & 5,3 & 6,0 & 5,0 & 4,8 & 5,3 & 4,7 & 4,7 & 4,6 \\
\hline VI & 8,2 & 4,4 & 10,7 & 8,8 & 5,0 & 13,1 & 9,0 & 6,2 & 14,5 & 9,1 & 7,2 & 14,8 \\
\hline VII & 7,1 & 3,6 & 9,3 & 7,0 & 3,4 & 10,9 & 6,1 & 3,1 & 12,3 & 5,7 & 3,4 & 12,7 \\
\hline VIII & 17,3 & 11,1 & 21,6 & 14,8 & 10,1 & 20,2 & 11,4 & 8,3 & 17,7 & 9,7 & 7,5 & 18,5 \\
\hline $\begin{array}{l}\text { Minas } \\
\text { Gerais }\end{array}$ & 100,0 & 100,0 & 100,0 & 100,0 & 100,0 & 100,0 & 100,0 & 100,0 & 100,0 & 100,0 & 100,0 & 100,0 \\
\hline
\end{tabular}

Quadro 3: Participação relativa das regiões nos totais de população.

Chart 3: Relative distribution of population by region.

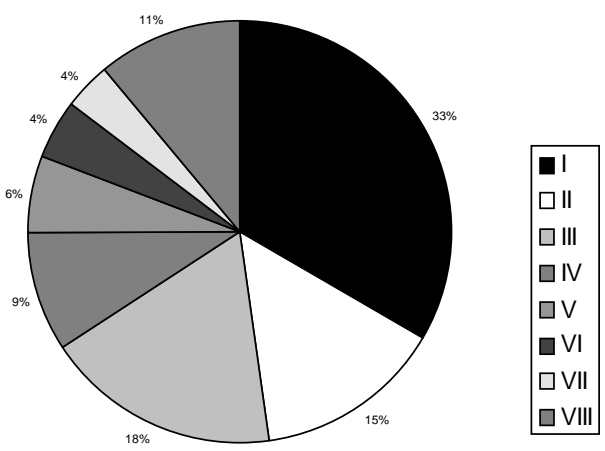

Gráfico 2: Participação das Regiões no total de população urbana no ano de 1960.

Grafic 2: Relative distribution of population by region in 1960.

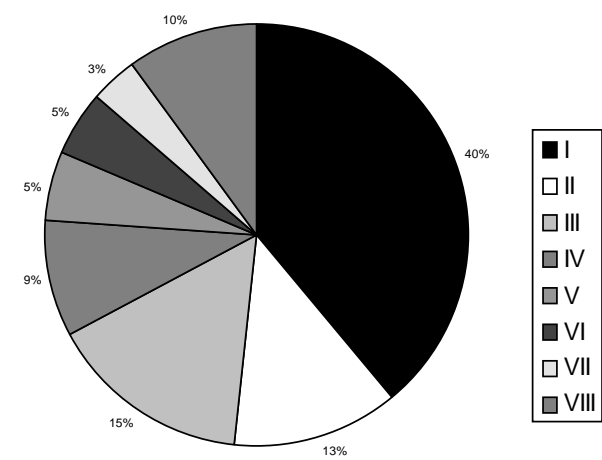

Gráfico 3: Participação das Regiões no total de população urbana no ano de 1970.

Grafic 3: Relative distribution of population by region in 1970.

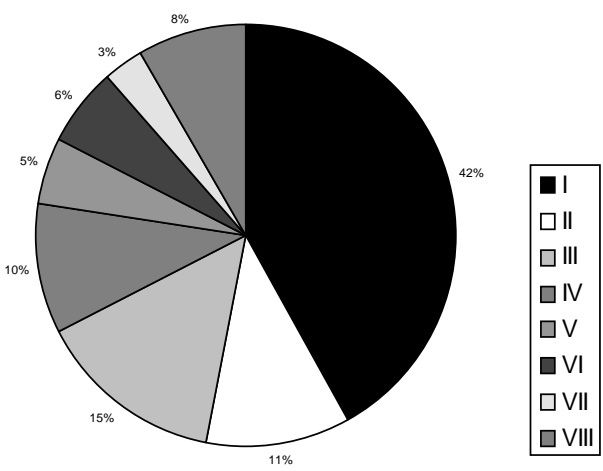

Gráfico 4: Participação das Regiões no total de população urbana no ano de 1980.

Grafic 4: Relative distribution of population by regions in 1980.

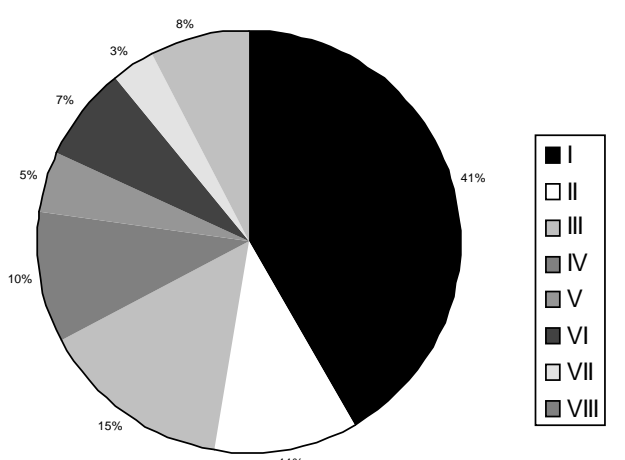

Gráfico 5: Participaçâao das Regiões no total de população urbana no ano de 1991.

Grafic 5: Relative distribution of population by region in 1991. 
A Região VI (Noroeste) com uma taxa de 97,1\% e a Região IV (Triângulo) com 51,5\% foram as regiões que tiveram maiores índices de crescimento de população urbana entre 1980 e 1991, confirmando a tendência já registradas nas décadas anteriores.

Tomando-se como índice básico a taxa de crescimento da população urbana do Estado na década $1980 / 1991$, que foi de $31,0 \%$, pode-se considerar as Regiões VI (Noroeste), IV (Triângulo), III (Sul), VII (Jequitinhonha), V (Alto São Francisco), II (Mata) como de forte crescimento urbano. As demais regiões tiveram taxas de crescimento inferiores ao índice estadual.

\section{POPULAÇÃO RURAL}

Com relação à população rural, a tendência é exatamente oposta à da população urbana: uma redução sistemática a partir de 1960.

Todas as regiões do Estado perderam população rural entre 1970 e 1980. As maiores perdas relativas foram as das regiões IV $(-31,1 \%)$, V $(-29,1 \%)$ e VIII (-28,8\%). Entre 1980 e 1991, com exceção da Região I, todas as regiões continuaram a perder população rural, porém essas perdas foram menos significativas do que em relação à década passada.

Nas décadas de 1970/1980 e 1980/1991 a Região VII (Jequitinhonha) foi a que registrou as menores perdas, tanto absoluta quanto relativa, o que coincide com o seu grau de urbanização que é o mais baixo do Estado. Isto nos obriga a uma reflexão mais cuidadosa pois a Região do Jequitinhonha é, notoriamente, classificada como uma das principais expulsoras de população do interior do Estado.

Entre a década de 1980/1991, a Região I (Metalúrgica) obteve um aumento absoluto da população Rural de 26.757 habitantes ou de 5\%. Esse fenômeno pode ser explicado através de um processo chamado de Desconcentração Urbana. Nesse processo que ocorre na Região Metropolitana de Belo Horizonte, as classes mais abastadas da população estão se deslocando do núcleo urbano para condomínios fechados, localizados em zonas rurais dos municípios que compõem a Grande Belo Horizonte.

Na década de 1960/1970, o índice de crescimento da população rural do Estado foi negativo $(-8,4 \%)$, caindo ainda mais na década $1970 / 1980$ para $(-18,8 \%)$ e no ano de 1991 chegou a $(-10,7 \%)$.

Esta queda reflete o enorme êxodo rural que tem caracterizado o Estado a partir de 1960, provocando, inclusive, uma diminuição da população em números absolutos: 5.925 .866 pessoas em 1960; $5.427 .115 \mathrm{em}$ $1970,4.404 .539$ em 1980 e 3.931 .613 em 1991.

\section{PARTICIPAÇÃO RELATIVA DAS REGIÕES NO INCREMENTO POPULACIONAL URBANO DE MINAS GERAIS}

O aumento da população urbana em Minas Gerais entre os anos de 1960/1970 foi de 2.173 .814 pessoas e entre 1970/1980 atingiu 2.925.966 pessoas e na década de 1980/1991 aumentou em 2.784.715.

Nos três períodos analisados a Região I (Metalúrgica) deteve a primazia absoluta na participação do aumento da população urbana com $48,8 \%$ do total na década $1960 / 1970,48,2 \%$ na década 1970/1980 e 40,3\% na década 1980/1991. As menores participações são das Regiões V, VII e VIII que podemos chamar de menos urbanizadas (Quadro 4).

Quase todas as regiões, tiveram aumento de participação no período analisado, com exceção da Região VIII que teve uma diminuição, passando de 8,4\% para 5,0\% e da Região I cuja participação relativa diminuiu de $48,8 \%$ para $40,3 \%$ do total de população urbana do Estado.

Estas variações, conforme já foi mencionado, podem significar uma reorientação do fluxo de população urbana, ou do processo de urbanização, dentro do território mineiro.

\begin{tabular}{|c|c|c|c|c|c|c|}
\hline \multirow{3}{*}{ REGIÃO } & \multicolumn{2}{|c|}{ PERÍODO } & \multicolumn{2}{|c|}{ PERÍODO } & \multicolumn{2}{|c|}{ PERÍODO } \\
\hline & \multicolumn{2}{|c|}{$1960 / 1970$} & \multicolumn{2}{|c|}{$1970 / 1980$} & \multicolumn{2}{|c|}{$1980 / 1991$} \\
\hline & incremento & $\%$ & incremento & $\%$ & incremento & $\%$ \\
\hline I & 1062042 & 48,8 & 1408796 & 48,2 & 1123873 & 40,3 \\
\hline II & 215359 & 9,9 & 218091 & 7,5 & 280142 & 10,1 \\
\hline III & 231841 & 10,6 & 372006 & 12,7 & 420296 & 15,1 \\
\hline IV & 194746 & 9,0 & 353805 & 12,1 & 283475 & 10,2 \\
\hline V & 90587 & 4,2 & 108498 & 3,7 & 129376 & 4,6 \\
\hline VI & 132053 & 6,1 & 252773 & 8,6 & 293681 & 10,5 \\
\hline VII & 65185 & 3,0 & 79291 & 2,7 & 116922 & 4,2 \\
\hline VIII & 182001 & 8,4 & 132706 & 4,5 & 136948 & 5,0 \\
\hline Minas Gerais & 2173814 & 100,0 & 2925966 & 100,0 & 2784715 & 100,0 \\
\hline
\end{tabular}

Quadro 4: Aumento de população urbana e participação relativa das regiões.

Chart 4: Increase of urban population and relative distribution by region. 


\section{O GRAU DE URBANIZAÇÃO}

No quadro 5 pode - se observar que, somente a partir de 1970, Minas Gerais passou a ter maior parte de população urbana. Em 1960, o grau de urbanização do Estado era de 39,6\% passando a 52,7\% em 1970, 67,1\% em 1980 e 74,9\% em 1991.

O aumento relativo, foi, portanto, de $35,3 \%$ no período de 30 anos. Nas duas primeiras décadas estudadas o acréscimo foi praticamente o mesmo $13,1 \%$ e $14,4 \%$, respectivamente. Na última década o aumento foi menor que os registrados anteriormente $7,8 \%$.

Em 1960, pouco mais de um terço da população mineira residia em cidades, sendo que a Região I era a única que tinha a maior parte de sua população urbana, alcançando um grau de urbanização de 65,8\%.

Todas as demais regiões possuíam menos de $50 \%$ de população urbana sendo que, entre elas, apenas as Regiões III e IV suplantavam o índice estadual, com $40,0 \%$ de população urbana. Duas destas regiões, a Noroeste e a Jequitinhonha, eram as mais "rurais", com apenas $21,2 \%$ e $20,1 \%$ de população urbana, respectivamente.

Dez anos depois (1970), a população urbana de Minas Gerais correspondia a $52,7 \%$ do total. Neste período, a população urbana cresceu em ritmo bem superior à população total: $55,9 \%$ contra $17,1 \%$. A participação da população urbana sobre a total apresentou, em 1970, um ganho relativo da ordem de $13,1 \%$ em relação ao total de 1960.

A exemplo do período anterior, a Região I (Metalúrgica) continuou a liderar os graus regionais de urbanização, atingindo 78,9\% de população urbana. Ocupando a segunda posição aparece a Região IV (Triângulo) com 60,1\% de população urbana, seguida pela Região III (Sul) cujo grau de urbanização foi de $50,8 \%$.

As demais regiões não conseguiram atingir ainda índices superiores a $50 \%$ de urbanização, sendo que as Regiões VI e VII continuavam a ocupar as posições menos urbanizadas do Estado, com $29,8 \%$ e $25,6 \%$, respectivamente, de população urbana.

Em 1980, a população urbana do Estado atinge $67,1 \%$ do total, representando um acréscimo de $14,4 \%$ em relação ao índice de 1970. A taxa de crescimento da população urbana neste período (1970/1980), decaiu para $48,3 \%$, bem inferior à taxa registrada na década anterior que foi de $55,9 \%$.

A população urbana da Região I, continua a crescer, correspondendo a 87,5\% do total. As demais regiões mantiveram as mesmas posições do período anterior, destacando-se a Região IV com $78,2 \%$ de população urbana.

As Regiões VI, VII e VIII continuavam a ter menos de $50 \%$ de população urbana, sendo que a Região VII (Jequitinhonha) manteve-se na condição de menos urbanizada do Estado, com apenas $34,4 \%$ de população urbana.

Em 1991, o grau de urbanização do Estado atinge $74,9 \%$ do total, o crescimento em relação a década passada foi de 7,8\%, o menor já registrado. Novamente a taxa de crescimento da população urbana desse período (1980/1991), decai, como na década anterior, chegando aos $31 \%$, a menor taxa entre os três períodos estudados.

A Região I (Metalúrgica), continua a ser a região mais urbanizada, mas, seu crescimento foi de apenas $2,1 \%$ em relação a década anterior. A Região IV (Triângulo), atingiu 85\% de urbanização, confirmando sua posição na década anterior como a segunda mais urbanizada. As demais regiões também cresceram com destaque para a Região VI (Noroeste) com um crescimento de cerca de 13\% entre 1980/1991.

Apenas a Região VII (Jequitinhonha), continua a possuir menos de $50 \%$ de população urbana, apesar de ter obtido um crescimento de $10,1 \%$, atingindo $44,5 \%$ de população urbanizada.

Excetuando-se a Região I, o menor crescimento do grau de urbanização foi o da Região IV (Triângulo), com $7 \%$ de crescimento na última década.

\section{AS CIDADES POR FAIXAS DE POPULAÇÃO}

Uma vez analisado o crescimento de população urbana e sua dinâmica a nível regional, estudar-se-a o comportamento das cidades mineiras nas três décadas analisadas, procurando ver quais as faixas de tamanho de cidades que mais cresceram no período e que seriam,

\begin{tabular}{|c|c|c|c|c|c|c|c|c|}
\hline REGIÃO & $1960(\%)$ & $1970(\%)$ & $\Delta(\%)$ & $1980(\%)$ & $\Delta(\%)$ & $1991(\%)$ & $\Delta(\%)$ & 1960 a $1991 \Delta(\%)$ \\
\hline I & 65,8 & 78,9 & 13,1 & 87,5 & 8,6 & 89,6 & 2,1 & 23,8 \\
\hline II & 36,6 & 49,2 & 12,6 & 60,5 & 11,3 & 69,2 & 8,7 & 32,6 \\
\hline III & 40,0 & 50,8 & 10,8 & 62,7 & 11,9 & 71,6 & 8,9 & 31,6 \\
\hline IV & 48,6 & 60,1 & 11,5 & 78,2 & 18,1 & 85,0 & 6,8 & 36,4 \\
\hline V & 36,6 & 49,4 & 12,8 & 64,8 & 15,4 & 75,6 & 10,8 & 39,0 \\
\hline VI & 21,2 & 29,8 & 8,6 & 46,5 & 16,7 & 59,3 & 12,8 & 38,1 \\
\hline VII & 20,1 & 25,6 & 5,5 & 34,4 & 8,8 & 44,5 & 10,1 & 24,4 \\
\hline VIII & 25,2 & 35,8 & 10,6 & 48,8 & 13,0 & 57,6 & 8,8 & 32,4 \\
\hline $\begin{array}{l}\text { Minas } \\
\text { Gerais }\end{array}$ & 39,6 & 52,7 & 13,1 & 67,1 & 14,4 & 74,9 & 7,8 & 35,3 \\
\hline
\end{tabular}


portanto, objeto de acompanhamento e ações de planejamento urbano especiais.

Em 1960, Minas Gerais contava com 483 cidades (sedes municipais). Em 1970, como decorrência da redivisão administrativa ocorrida em 1962, o número de cidades passou a 722, inalterado até 1991 (Quadro 6).

Nos quatro momentos analisados, a urbanização mineira se caracterizou por uma grande dispersão, num elevado número de pequenas cidades e, por outro lado, numa concentração em um reduzido número de cidades maiores.

Em 1960, o Estado tinha 418 cidades com menos de 10 mil habitantes, representando $86,8 \%$ do total de cidades e concentrando apenas $35,9 \%$ da população urbana do Estado, ou seja, 1.217.736 pessoas.

Belo Horizonte, com 642.912 habitantes, representava $19 \%$ da população das cidades mineiras. A malha urbana intermediária, correspondente às cidades de 10 a 50 mil habitantes, era pouco expressiva, somando 59 cidades (12,2\% do total) e correspondendo a $35,1 \%$ da população urbana, ou seja, 1.190.221 habitantes.

Em 1970, o grupo de cidades com menos de 10 mil habitantes aumenta a sua participação e passa a representar $87,4 \%$ do total de cidades (630 cidades), diminuindo entretanto, a sua participação no total de população urbana, com um percentual de apenas $29,9 \%$. No outro extremo, Belo Horizonte reforça sua posição de cidade primaz, passando a deter $19,8 \%$ do total de população das cidades mineiras.

A representatividade das cidades mineiras de 10 a 50 mil habitantes diminui, tanto em número $(10,8 \%$ do total), como em população ( $33,2 \%$ do total).

Neste ano (1970), o Estado já possuía 11 cidades com mais de 50 mil habitantes, enquanto que em 1960 elas eram em número de 5.

Em 1980, a posição do grupo de cidades com mais de 10 mil habitantes foi a seguinte: $81,5 \%$ do número de cidades, ou seja, 589 cidades, e $22,6 \%$ da população urbana mineira, o que corresponde, em número absoluto, a 1.762.211 pessoas. Como pode-se verificar (Quadro 7), ambos os índices diminuíram, em relação aos de 1970, representando uma menor participação deste grupo, no número total de cidades e no total de população de cidades mineiras.

\begin{tabular}{|c|c|c|c|c|c|c|c|c|}
\hline \multirow{2}{*}{$\begin{array}{c}\text { GRUPOS DE } \\
\text { HABITANTES } \\
\end{array}$} & \multicolumn{4}{|c|}{ NÚMERO } & \multicolumn{4}{|c|}{ POPULAÇÃO } \\
\hline & 1960 & 1970 & 1980 & 1991 & 1960 & 1970 & 1980 & 1991 \\
\hline até 500 & 3 & 20 & 15 & 5 & 1225 & 7836 & 6126 & 2232 \\
\hline de 501 a 1000 & 41 & 130 & 93 & 50 & 33921 & 97387 & 72867 & 41048 \\
\hline de 1001 a 2000 & 134 & 183 & 155 & 132 & 197419 & 269629 & 229405 & 190170 \\
\hline de 2001 a 5000 & 173 & 207 & 221 & 233 & 530434 & 641096 & 710245 & 749788 \\
\hline de 5001 a 10000 & 67 & 90 & 105 & 127 & 454737 & 625864 & 743568 & 877146 \\
\hline de 10001 a 20000 & 34 & 46 & 64 & 87 & 467158 & 653648 & 832653 & 1198037 \\
\hline de 20001 a 50000 & 25 & 35 & 43 & 56 & 723063 & 1127642 & 1318250 & 1845491 \\
\hline de 50001 a 100000 & 3 & 6 & 14 & 20 & 213266 & 386799 & 1095910 & 1406383 \\
\hline de 100001 a 200000 & 1 & 3 & 6 & 7 & 124979 & 343452 & 831000 & 1064622 \\
\hline de 200001 a 500000 & - & 1 & 2 & 4 & - & 218856 & 530128 & 1167318 \\
\hline de 500001 a1000000 & 1 & - & - & - & 642912 & - & - & - \\
\hline mais de 1000000 & - & 1 & 1 & 1 & - & 1106967 & 1442483 & 1531186 \\
\hline TOTAL & 483 & 722 & 722 & 722 & 3389114 & 5479176 & 7812635 & 10073421 \\
\hline
\end{tabular}

\begin{tabular}{|c|c|c|c|c|c|c|}
\hline \multirow{2}{*}{$\begin{array}{c}\text { GRUPO DE } \\
\text { HABITANTES }\end{array}$} & \multicolumn{2}{|c|}{$1960 / 1970$} & \multicolumn{2}{|c|}{ 1970/1980 } & \multicolumn{2}{|c|}{ 1980/1991 } \\
\hline & número & pop. & número & pop. & número & pop. \\
\hline $\begin{array}{l}\text { até } 500 \\
\text { de } 501 \text { a } 1000 \\
\text { de } 1001 \text { a } 2000 \\
\text { de } 2001 \text { a } 5000 \\
\text { de } 5001 \text { a } 10000 \\
\text { de } 10001 \text { a } 20000 \\
\text { de } 20001 \text { a } 50000 \\
\text { de } 50001 \text { a } 100000 \\
\text { de } 100001 \text { a } 200000 \\
\text { de } 200001 \text { a } 500000 \\
\text { mais de } 500000\end{array}$ & $\begin{array}{l}\text { aumentou } \\
\text { aumentou } \\
\text { aumentou } \\
\text { aumentou } \\
\text { aumentou } \\
\text { aumentou } \\
\text { aumentou } \\
\text { aumentou } \\
\text { aumentou } \\
\text { aumentou } \\
\text { aumentou }\end{array}$ & $\begin{array}{l}\text { aumentou } \\
\text { aumentou } \\
\text { aumentou } \\
\text { aumentou } \\
\text { aumentou } \\
\text { aumentou } \\
\text { aumentou } \\
\text { aumentou } \\
\text { aumentou } \\
\text { aumentou } \\
\text { aumentou }\end{array}$ & $\begin{array}{l}\text { diminuiu } \\
\text { diminuiu } \\
\text { diminuiu } \\
\text { aumentou } \\
\text { aumentou } \\
\text { aumentou } \\
\text { aumentou } \\
\text { aumentou } \\
\text { aumentou } \\
\text { aumentou } \\
\text { estabilisou }\end{array}$ & $\begin{array}{l}\text { diminuiu } \\
\text { diminuiu } \\
\text { diminuiu } \\
\text { aumentou } \\
\text { aumentou } \\
\text { aumentou } \\
\text { aumentou } \\
\text { aumentou } \\
\text { aumentou } \\
\text { aumentou } \\
\text { aumentou }\end{array}$ & $\begin{array}{l}\text { diminuiu } \\
\text { diminuiu } \\
\text { diminuiu } \\
\text { aumentou } \\
\text { aumentou } \\
\text { aumentou } \\
\text { aumentou } \\
\text { aumentou } \\
\text { aumentou } \\
\text { aumentou } \\
\text { estabilisou }\end{array}$ & $\begin{array}{l}\text { diminuiu } \\
\text { diminuiu } \\
\text { diminuiu } \\
\text { aumentou } \\
\text { aumentou } \\
\text { aumentou } \\
\text { aumentou } \\
\text { aumentou } \\
\text { aumentou } \\
\text { aumentou } \\
\text { aumentou }\end{array}$ \\
\hline
\end{tabular}


A posição de Belo Horizonte também declina, passando a representar $18 \%$ da população urbana do Estado (1.442.483 habitantes).

O grupo de cidades intermediárias, ou seja, de 10 a 50 mil habitantes, corresponde a $14,9 \%$ do total de cidades e a $27,1 \%$ da população urbana total. Em relação a 1970, elas crescem em participação numérica mas diminuem na participação demográfica.

Em compensação, o número de cidades na faixa de 50 a 500 mil habitantes, aumentou para 22, passando a representar 31,7\% da população das cidades.

Em 1991, as cidades que pertencem ao grupo correspondente a menos de 10 mil habitantes, somavam 547 cidades, ou seja, $75,7 \%$ do total de cidades e $18,5 \%$ da população urbana do Estado. Em relação aos índices de 1980, a participação desse grupo diminuiu em ambos os casos.

Nesse ano, Belo Horizonte detinha 15,2\% da população urbana do Estado, correspondendo a um contingente de 1.531.186 habitantes. Essa participação é menor que a registrada no ano de 1980.

As cidades correspondentes a faixa de 10 a $50 \mathrm{mil}$ habitantes, aumentaram a sua participação em relação a 1980 para $19,8 \%$ e a população urbana total atingiu os $30,1 \%$.

As cidades situadas na faixa de 50 a $500 \mathrm{mil}$ habitantes, aumentaram para 31, representando agora $36,2 \%$ da população urbana do Estado.

A análise detalhada da evolução da população urbana das cidades, divididas por faixas de população, nos mostra comportamentos diferentes nas três décadas referidas.

Na década de 1960/1970, o crescimento da população residente nas cidades mineiras foi de 2.090.062 habitantes, sendo que as pequenas sedes municipais, com população entre 500 e 2.000 habitantes, aparecem com modesta participação neste crescimento, inferiores a $7 \%$ na década.
A maior participação pertence a Belo Horizonte, responsável por $22,2 \%$ do crescimento e ao grupo de cidades de 20 a 50 mil habitantes com 19,37\% do total.

No período seguinte, 1970/1980, os maiores incrementos populacionais ocorrem no grupo de cidades de 50 a 100 mil habitantes, responsáveis por $30,4 \%$ do aumento total.

As pequenas cidades, de menos de 2.000 mil habitantes, tiveram sua população diminuída, apresentando, consequentemente, participação negativa no aumento de população urbana do Estado.

Na última década analisada 1980/1991, o aumento da população residente nas cidades do Estado foi de 2.089.686 habitantes, um contingente menor que o da década anterior, que obteve um incremento de 2.333.459.

As faixas que contribuíram para os maiores incrementos foram as de 200 a 500 mil habitantes, com $30,5 \%$ de crescimento e o grupo de 20 a 50 mil habitantes, que atingiu $25,2 \%$ do crescimento total.

Novamente, as pequenas cidades com menos de 20.000 habitantes, tiveram sua população diminuída, pois seu crescimento foi ainda mais negativo que o da década passada.

Os dados dos quadros 8 e 9 mostram algumas tendências bem evidentes da dinâmica urbana do Estado: um esvaziamento das cidades pequenas; uma perda de dinamismo de Belo Horizonte; e uma concentração de população nas cidades intermediárias.

\section{DISTRIBUIÇÃO REGIONAL DAS CIDADES COM MAIS DE 20.000 E DE MENOS DE 20.000 HABITANTES}

Partindo-se do suposto de que 20 mil habitantes é o limite inferior mínimo que separa as cidades médias das cidades pequenas ${ }^{2}$, estudaremos este grupo de cidades em particular, observando a dinâmica de seu crescimento e a sua distribuição espacial.

\begin{tabular}{|c|c|c|c|c|c|c|c|c|c|c|c|c|c|c|c|c|}
\hline \multirow{3}{*}{ GRUPOS DE HABITANTES } & \multicolumn{4}{|c|}{1960} & \multicolumn{4}{|c|}{1970} & \multicolumn{4}{|c|}{1980} & \multicolumn{4}{|c|}{1991} \\
\hline & \multicolumn{2}{|c|}{ número } & \multicolumn{2}{|c|}{ população } & \multicolumn{2}{|c|}{ número } & \multicolumn{2}{|c|}{ população } & \multicolumn{2}{|c|}{ número } & \multicolumn{2}{|c|}{ população } & \multicolumn{2}{|c|}{ número } & \multicolumn{2}{|c|}{ população } \\
\hline & simples & acum. & simples & acum. & simples & acum. & simples & acum. & simples & acum. & simples & acum. & simples & acum. & simples & acum. \\
\hline até 500 & 0,6 & - & 0,1 & - & 2,5 & - & 0,1 & _ & 2,0 & _ & 0,1 & _ & 0,7 & - & 0,1 & _- \\
\hline de 501 a 1000 & 8,5 & 9,1 & 1,0 & 1,1 & 17,8 & 20,3 & 1,7 & 1,8 & 12,9 & 14,9 & 0,9 & 1,0 & 6,9 & 7,6 & 0,4 & 0,5 \\
\hline de 1001 a 2000 & 28,0 & 37,1 & 5,8 & 6,9 & 25,2 & 45,5 & 4,8 & 6,6 & 21,5 & 36,4 & 2,9 & 3,9 & 18,3 & 25,9 & 1,9 & 2,4 \\
\hline de 2001 a 5000 & 35,8 & 72,9 & 15,6 & 22,5 & 29,0 & 74,5 & 11,6 & 18,2 & 30,6 & 67,0 & 9,1 & 13,0 & 32,2 & 58,1 & 7,4 & 9,8 \\
\hline de 5001 a 10000 & 13,9 & 86,8 & 13,4 & 35,9 & 12,9 & 87,4 & 11,7 & 29,9 & 14,5 & 81,5 & 9,6 & 22,6 & 17,6 & 75,7 & 8,7 & 18,5 \\
\hline de 10001 a 20000 & 7,0 & 93,8 & 13,8 & 49,7 & 6,2 & 93,6 & 11,6 & 41,5 & 8,9 & 90,4 & 10,8 & 33,4 & 12,0 & 87,7 & 11,9 & 30,4 \\
\hline de 20001 a 50000 & 5,2 & 99,0 & 21,3 & 71,0 & 4,6 & 98,2 & 21,6 & 63,1 & 6,0 & 96,4 & 16,9 & 50,3 & 7,8 & 95,5 & 18,2 & 48,6 \\
\hline de 50001 a 100000 & 0,6 & 99,6 & 6,3 & 77,3 & 1,2 & 99,4 & 7,0 & 70,1 & 2,4 & 98,8 & 14,2 & 64,5 & 2,8 & 98,3 & 14,0 & 62,6 \\
\hline de 100001 a 200000 & 0,2 & 99,8 & 3,7 & 81,0 & 0,4 & 99,8 & 6,2 & 76,1 & 0,8 & 99,6 & 10,7 & 75,2 & 1,0 & 99,3 & 10,6 & 73,2 \\
\hline de 200001 a 500000 & - & - & - & - & 0,1 & 99,9 & 3,9 & 80,2 & 0,3 & 99,9 & 6,8 & 82,0 & 0,6 & 99,9 & 11,6 & 84,8 \\
\hline de 500001 a 1000000 & 0,2 & 100,0 & 19,0 & 100,0 & - & - & - & - & - & - & - & - & - & - & - & - \\
\hline mais de 1 milhão & - & - & - & - & 0,1 & 100,0 & 19,8 & 100,0 & 0,1 & 100,0 & 18,0 & 100,0 & 0,1 & 100,0 & 100,0 & 100,0 \\
\hline total & 100,0 & 100,0 & 100,0 & 100,0 & 100,0 & 100,0 & 100,0 & 100,0 & 100,0 & 100,0 & 100,0 & 100,0 & 100,0 & 100,0 & 100,0 & 100,0 \\
\hline
\end{tabular}

Fonte: IBGE

Quadro 8: Participação relativa das cidades por faixas de população.

Chart 8: Relative distribution of the cities by population class.

2 - Oswaldo Bueno Amorim Filho et al - "Cidades de Porte Médio e o Programa de Ações Sócio - Educativo Culturais para as Populações Carentes do Meio Urbano em Minas Gerais " Belo Horizonte - 1980. 
Minas Gerais tinha, em 1960, 30 cidades com mais de 20 mil habitantes que concentravam 1.704.220 pessoas, o que correspondia a $50,3 \%$ do total de população das cidades mineiras.

Em 1970, o número destas cidades aumentou para 45 e elas passaram a somar $58,5 \%$ da população urbana do Estado.

Ao final de 1980, o total destas cidades atingiu 70, ou seja, mais do dobro do número de 1960. Em termos populacionais, a participação deste grupo aumentou para $66,6 \%$, registrando, portanto, um crescimento sistemático nos 20 anos.

Em 1991, Minas Gerais contava com 88 cidades contendo mais de 20.000 habitantes onde, residiam 7.015.000 habitantes. O crescimento no período de 1980/1991, não foi tão marcante quanto o ocorrido entre 1970 e 1980. Esse aumento elevou a participação desse grupo para 69,6\% do total da população urbana do Estado.

Por estes índices, esta faixa de cidades passa a ser merecedora de ações especiais de planejamento urbano, tanto na esfera federal, como na estadual ${ }^{3}$.

Analisando-se a distribuição deste grupo de cidades por Regiões de Planejamento, verifica-se que nos quatro momentos estudados, a Região I concentrou a maior parte dos centros com mais de 20 mil habitantes.

Em 1960, esta região possuía 8 cidades deste tamanho (26,7\% do total); em 1970, tinha 15 cidades (32,6\% do total); em 1980 este número passou para 22 cidades (31,9\% do total); e em 1991, contava com 30 cidades, ou seja, $34 \%$ do total.

Todavia, foi a Região VI (Noroeste) a que apresentou o maior crescimento numérico e populacional das cidades com mais de 20 mil habitantes: em 1960 e 1970, ela possuía apenas 1 cidade deste tamanho (Montes Claros); em 1980, existiam 6 cidades, que somavam 290.423 habitantes; e em 1991 essa região já contava com 9 cidades, demonstrando um forte crescimento numérico $(800,0 \%$ entre 1960 e 1991) e populacional $(1.132,4 \%$ entre 1960 e 1991) nessa faixa de tamanho.

A Região VII (Jequitinhonha) se caracterizou por ser a menos urbanizada do Estado: até 1970 não tinha nenhuma cidade com mais de 20 mil habitantes, em 1980 contava apenas com 1 cidade desse porte (Diamantina com 20.000 habitantes) e em 1991, possuía somente 2 cidades desta categoria.

Como o processo de urbanização parece ser irreversível, esta situação que foi descrita, não é, por certo, definitiva.

Uma rápida análise da faixa de cidades precedentes (10 a 20 mil habitantes) mostra tendências que às vezes não coincidem com a dinâmica observada até agora.

As Regiões III, IV, VI e a Região VII (descritas como de fraca urbanização), apresentaram significativo crescimento do número e de população das cidades entre 10 e 20 mil habitantes, principalmente nesta última década, onde, duplicaram em termos aproximados os seus totais. A Região VIII apresentou um crescimento pouco expressivo no último decênio (Quadro 10).

Na década de 1980/1991, as Regiões I, II e V que possuem uma situação estabilizada com referência a faixa de cidades de mais de 20 mil habitantes, tiveram uma redução do número de cidades ou permaneceram iguais no grupo de 10 a 20 mil habitantes.

\begin{tabular}{|c|c|c|c|c|c|c|c|c|}
\hline \multirow{3}{*}{ REGIÃO } & \multicolumn{8}{|c|}{ AGLOMERADOS URBANOS } \\
\hline & \multicolumn{2}{|c|}{1960} & \multicolumn{2}{|c|}{1970} & \multicolumn{2}{|c|}{1980} & \multicolumn{2}{|c|}{1991} \\
\hline & número & população & número & população & número & população & número & população \\
\hline I & 7 & 92097 & 7 & 109262 & 10 & 126038 & 8 & 113998 \\
\hline II & 5 & 70930 & 5 & 71171 & 5 & 66808 & 5 & 61711 \\
\hline III & 11 & 165149 & 10 & 145471 & 11 & 145015 & 22 & 287933 \\
\hline IV & 3 & 34795 & 5 & 72686 & 7 & 82984 & 13 & 175890 \\
\hline V & 3 & 36169 & 8 & 103098 & 13 & 184988 & 12 & 189674 \\
\hline VI & 2 & 24549 & 5 & 72765 & 5 & 66889 & 10 & 131158 \\
\hline VII & 1 & 14252 & 3 & 43289 & 7 & 87222 & 10 & 147046 \\
\hline VIII & 2 & 29521 & 3 & 35906 & 6 & 72716 & 7 & 90927 \\
\hline Minas Gerais & 34 & 467462 & 46 & 653648 & 64 & 832860 & 87 & 1198037 \\
\hline
\end{tabular}

3 - Pela Constituição de 1988 as cidades com mais de 20.000 habitantes ficam obrigadas a ter um Plano de Desenvolvimento Urbano (PDU). 


\section{DESTAQUES}

Em termos individuais, algumas cidades se destacam por seu expressivo e constante crescimento nas décadas analisadas (Quadro 12):

a) na década 60/70, destacam-se as cidades de Contagem, Itabira, Unaí, Montes Claros, e Frutal com taxas de crescimento superior a $100 \%$;

b) na década 70/80, destacam-se pela ordem, as cidades de Betim, Contagem, Janaúba, Unaí e Santa Luzia com as maiores taxas de crescimento;

c) na década de 80/91, destacam-se as cidades de Ribeirão das Neves, Ibirité, Ouro Branco, Betim e Várzea da Palma;

d) em todo o período analisado, 1960 a 1991, os maiores índices de crescimento pertencem às cidades de Contagem, Ipatinga, Betim, Ibirité, Ouro Branco e Ribeirão das Neves;

e) Belo Horizonte, aparece como cidade primaz nos quatro momentos analisados, com uma população muito superior à da cidade colocada em segundo lugar no ranking. A sua taxa geométrica de crescimento decaiu de $72,7 \%$ na década $1960 / 1970$ para $30,3 \%$ na década de 1970 a 1980 e na década de 1980/1991, diminui para $6,1 \%$, demostrando assim, um processo de retração em seu crescimento.

Comparando-se as taxas geométricas de crescimento populacional das cidades de mais de 20 mil habitantes, entre as décadas estudadas, podemos classificar as cidades em três grupos: as cidades em expansão, as cidades estagnadas e as cidades em retração. Entre 1960 e 1970 a situação era a seguinte:

Grupo 1 - Cidades que apresentam um maior crescimento na década de 70 em relação a de 60 (em expansão): Uberlândia, Uberaba, Araguari, Betim, Varginha, Passos, Araxá, Pouso Alegre, Ubá, Coronel Fabriciano, Caratinga, Alfenas, Pirapora, Campo Belo, Paracatu, Patrocínio, Viçosa, Leopoldina, Janaúba, São Sebastião do Paraíso, Santa Luzia, Três Pontas, Guaxupé, Contagem, Monte Carmelo;

Grupo 2 - Cidades que apresentam taxa de crescimento da década de 70 inferior à taxa da década de 60 (em retração): Belo Horizonte, Juiz de Fora,
Governador Valadares, Montes Claros, Divinópolis, Sete Lagoas, Teófilo Otoni, Barbacena, Ituiutaba, Itabira, Itajubá, São João del Rei, João Monlevade, Lavras, Timóteo, Cataguases, Formiga, Nanuque, Santos Dumont, Ouro Preto, Caeté, Além Paraíba, Itabira, Frutal, Sabará, Oliveira;

Grupo 3 - Cidades que apresentam taxas de crescimento pouco diferenciadas das duas últimas décadas (em estagnação): Patos de Minas, Muriaé, Itaúna, Pará de Minas, Três Corações, Nova Lima, Manhuaçu, Poços de Caldas.

Realizando novamente esta análise agora para as décadas de 70 e 80 a situação era a seguinte:

Grupo 1 - Cidades com população superior a 20 mil habitantes cujo crescimento esta expandindo: Itajubá, Lavras, Patrocínio, Nanuque, Santos Dumont, Ouro Preto, Guaxupé, Ibirité, Frutal, Bom Despacho, Além Paraíba, Diamantina, Várzea da Palma, Lagoa Santa e Carangola;

Grupo 2 - Cidades com população superior a 20 mil habitantes cujo crescimento esta retraído: Belo Horizonte, Juiz de Fora, Uberlândia, Montes Claros, Governador Valadares, Uberaba, Contagem, Betim, Divinópolis, Sete Lagoas, Ipatinga, Poços de Caldas, Teófilo Otoni, Conselheiro Lafaiete, Varginha, Araguari, Ituiutaba, Passos, Pouso Alegre, Itabira, Araxá, Muriaé, Itaúna, Ubá, Pará de Minas, Paracatu, Timóteo, Caratinga, Pirapora, Coronel Fabriciano, Unaí, Janaúba, Viçosa, São Sebastião do Paraíso, Campo Belo, Santa Luzia, Leopoldina, Três Pontas, Monte Carmelo, Vespasiano, Pedro Leopoldo, Januária, Congonhas, Itabirito, Lagoa da Prata, Caeté, Oliveira, Bocaiúva, Ouro Branco, Arcos, Almenara, João Pinheiro, Visconde do Rio Branco, Mariana, Piui, Matozinhos e Santa Rita do Sapucaí;

Grupo 3 - Cidades com população superior a 20 mil habitantes cujo crescimento esta estagnado: Patos de Minas, Barbacena, São João Del Rei, João Monlevade, Cataguases, Três Corações, Curvelo, Alfenas, Formiga, Nova Lima, Ponte Nova, Ribeirão das Neves, Manhuaçu, São Lourenço, Sabará e Boa Esperança.

\begin{tabular}{|c|c|c|c|c|c|c|c|c|c|}
\hline \multirow{2}{*}{ CIDADES } & \multirow{2}{*}{$\begin{array}{c}\text { REGIÃO DE } \\
\text { PLANEJA- } \\
\text { MENTO }\end{array}$} & \multirow{2}{*}{1960} & \multirow{2}{*}{1970} & \multirow{2}{*}{1980} & \multirow{2}{*}{1991} & \multicolumn{4}{|c|}{ TAXA DE CRESCIMENTO } \\
\hline & & & & & & 1960/70 & $1970 / 80$ & 1980/91 & 1960/91 \\
\hline Além Paraíba . & II & _- & 21743 & 23028 & 26202 & 18,1 & 5,9 & 13,8 & 42,4 \\
\hline Alfenas.. & III & _- & 20801 & 31815 & 47011 & 29,5 & 52,9 & 47,8 & 192,9 \\
\hline Almenara ..... & VII & _ & _ & _ & 23257 & $-16,8$ & 131,5 & 35,1 & 160,5 \\
\hline Araguari ....... & IV & 35520 & 48698 & 73302 & 80654 & 37,1 & 50,5 & 10,0 & 127,1 \\
\hline Araxá ............ & IV & 24041 & 31520 & 51339 & 67972 & 31,1 & 62,9 & 32,4 & 182,7 \\
\hline $\operatorname{Arcos} \ldots \ldots \ldots \ldots \ldots$ & $\mathrm{V}$ & - & - & - & 23469 & 69,7 & 73,9 & 38,7 & 309,4 \\
\hline Barbacena ......... & I & 41931 & 57767 & 69675 & 80760 & 37,8 & 20,6 & 15,9 & 92,6 \\
\hline Belo Horizonte. . . . . . . & I & 642912 & 1106967 & 1442483 & 1531186 & 72,2 & 30,3 & 6,1 & 138,2 \\
\hline
\end{tabular}




\begin{tabular}{|c|c|c|c|c|c|c|c|c|c|}
\hline \multirow{2}{*}{ CIDADES } & \multirow{2}{*}{$\begin{array}{c}\text { REGIÃO DE } \\
\text { PLANEJA- } \\
\text { MENTO }\end{array}$} & \multirow{2}{*}{1960} & \multirow{2}{*}{1970} & \multirow{2}{*}{1980} & \multirow{2}{*}{1991} & \multicolumn{4}{|c|}{ TAXA DE CRESCIMENTO } \\
\hline & & & & & & $1960 / 70$ & $1970 / 80$ & $1980 / 91$ & $1960 / 91$ \\
\hline Betim .......... & $\bar{I}$ & - & - & 71599 & 162143 & 95,6 & 307,3 & 126,4 & 1709,0 \\
\hline Boa Esperança .......... & III & - & - & - & 25267 & 33,0 & 43,3 & 43,0 & 172,8 \\
\hline Bocaiúva............. & VI & - & - & - & 24791 & 60,4 & 75,3 & 48,1 & 316,5 \\
\hline Bom Despacho ......... & $\mathrm{V}$ & - & - & 22941 & 29520 & 38,2 & 22,3 & 28,9 & 117,6 \\
\hline Caeté........... & I & - & - & 23331 & 27532 & 71,0 & 25,8 & 18,0 & 154,0 \\
\hline Campo Belo ....... & III & - & 20139 & 30392 & 39644 & 27,9 & 50,9 & 30,4 & 151,8 \\
\hline Carangola .... & II & - & - & - & 20216 & 27,7 & 4,7 & 27,1 & 69,9 \\
\hline Caratinga ......... & VIII & 22775 & 28175 & 39621 & 46543 & 23,7 & 40,6 & 17,5 & 104,4 \\
\hline Cataguases... & II & 21476 & 32476 & 40659 & 50986 & 51,2 & 25,2 & 25,4 & 137,4 \\
\hline Congonhas ............ & I & - & - & 22623 & 28443 & 73,8 & 86,7 & 25,7 & 308,1 \\
\hline Conselheiro Lafaiete ...... . & I & 29208 & 44959 & 66262 & 82820 & 53,9 & 47,4 & 25,0 & 183,5 \\
\hline Contagem $\ldots \ldots \ldots \ldots$ & I & - & 27533 & 111697 & 195927 & 642,5 & 305,7 & 75,4 & 5183,9 \\
\hline Coronel Fabriciano ....... & I & - & 23456 & 41258 & 44029 & 60,4 & 75,9 & 6,7 & 201,1 \\
\hline Curvelo...... & $\mathrm{V}$ & 21722 & 30194 & 37734 & 47080 & 38,7 & 25,0 & 24,8 & 116,2 \\
\hline Diamantina .... & VII & - & - & 20197 & 26074 & 24,0 & 14,2 & 29,1 & 83,0 \\
\hline Divinópolis ........ & I & 41544 & 69873 & 108344 & 142061 & 68,2 & 55,8 & 31,1 & 241,9 \\
\hline Formiga $\ldots \ldots \ldots \ldots \ldots$ & III & - & 28765 & 36681 & 46638 & 52,8 & 27,9 & 27,1 & 148,6 \\
\hline Frutal $\ldots \ldots \ldots \ldots \ldots$ & IV & - & - & 22955 & 31980 & 104,8 & 35,8 & 39,3 & 287,5 \\
\hline Governador Valadares.... & VIII & 70494 & 124904 & 173699 & 210513 & 77,2 & 39,1 & 21,2 & 198,6 \\
\hline Guaxupé & III & - & - & 23637 & 34368 & 22,1 & 36,5 & 45,4 & 142,6 \\
\hline Ibirité ........ & I & - & - & - & 33313 & 23,4 & 214,5 & 327,5 & 1654,2 \\
\hline Ipatinga . & I & - & - & 106980 & 120300 & 354,8 & 497,9 & 12,4 & 2957,9 \\
\hline Itabira $\ldots \ldots \ldots \ldots \ldots \ldots$ & I & - & 40106 & 57691 & 71578 & 158,0 & 43,8 & 24,1 & 360,6 \\
\hline Itabirito $\ldots \ldots \ldots$ & I & - & - & 22978 & 28246 & 65,9 & 31,7 & 22,9 & 168,7 \\
\hline Itajubá ............. & III & 31262 & 42477 & 53506 & 68856 & 35,9 & 26,0 & 28,7 & 120,2 \\
\hline Itaúna .......... & I & 22319 & 32176 & 49372 & 61946 & 46,6 & 50,9 & 25,5 & 177,5 \\
\hline Ituiutaba $\ldots \ldots \ldots \ldots \ldots$ & IV & 29724 & 47114 & 65178 & 78205 & 58,5 & 38,3 & 20,0 & 163,1 \\
\hline Janaúba .......... & VI & - & - & 28466 & 40814 & 98,1 & 184,1 & 43,4 & 707,4 \\
\hline Januária $\ldots \ldots \ldots \ldots \ldots$ & VI & - & - & 20484 & 28762 & 39,5 & 50,6 & 40,4 & 195,3 \\
\hline João Monlevade . . . . . . . . & I & - & 38656 & 47225 & 57407 & 42,9 & 22,2 & 21,6 & 112,3 \\
\hline João Pinheiro . . . & VI & - & - & - & 22945 & 155,8 & 97,0 & 32,6 & 568,4 \\
\hline Juiz de Fora. & II & 124979 & 218856 & 299728 & 377790 & 75,1 & 37,0 & 26,0 & 202,3 \\
\hline Lagoa da Prata ... & $\mathrm{V}$ & - & - & 20069 & 28128 & 81,6 & 61,3 & 40,0 & 310,1 \\
\hline Lagoa Santa ...... & I & - & - & - & 22797 & 18,5 & 53,7 & 66,2 & 202,7 \\
\hline Lavras .. & III & 23793 & 35489 & 43545 & 60730 & 49,2 & 27,8 & 39,5 & 155,2 \\
\hline Leopoldina . & II & - & 21152 & 28554 & 34886 & 19,3 & 35,0 & 22,2 & 96,8 \\
\hline Manhuaçu ............. & II & - & - & 22678 & 33500 & 45,0 & 48,2 & 47,7 & 217,6 \\
\hline Mariana ........ & I & - & - & - & 20994 & $-9,9$ & 111,8 & 72,5 & 229,2 \\
\hline Matozinhos ..... & I & - & - & - & 20300 & 68,6 & 108,2 & 52,8 & 436,2 \\
\hline Monte Carmelo . . . . . . . . . & IV & - & - & 21659 & 29532 & 34,1 & 61,1 & 36,3 & 194,8 \\
\hline Montes Claros ........... & VI & 40545 & 81657 & 151881 & 223491 & 101,4 & 86,0 & 47,1 & 451,2 \\
\hline Muriaé...$\ldots \ldots \ldots \ldots$ & II & 22571 & 33917 & 50040 & 65468 & 50,3 & 47,5 & 30,8 & 190,0 \\
\hline Nanuque...$\ldots \ldots \ldots$ & VIII & - & 34565 & 34445 & 37095 & 91,2 & $-0,3$ & 7,7 & 105,2 \\
\hline Nova Lima ............ & I & 21135 & 27377 & 35053 & 44038 & 29,5 & 28,0 & 25,6 & 108,4 \\
\hline Oliveira...$\ldots \ldots \ldots \ldots$ & III & - & - & 22642 & 25358 & 43,6 & 21,9 & 12,0 & 96,3 \\
\hline Ouro Branco . & I & - & - & - & 23631 & $-40,4$ & 636,4 & 167,9 & 1075,7 \\
\hline Ouro Preto . & I & - & 24043 & 27821 & 35241 & 63,3 & 15,7 & 26,7 & 139,4 \\
\hline Pará de Minas . & I & - & 24036 & 37127 & 51822 & 51,5 & 54,5 & 39,6 & 226,8 \\
\hline Paracatu $\ldots \ldots \ldots \ldots \ldots$ & VI & - & - & 29911 & 49710 & 63,8 & 71,0 & 36,1 & 365,6 \\
\hline Passos ............. & III & 28555 & 39059 & 56998 & 74223 & 36,8 & 45,9 & 30,2 & 159,9 \\
\hline
\end{tabular}




\begin{tabular}{|c|c|c|c|c|c|c|c|c|c|}
\hline \multirow{2}{*}{ CIDADES } & \multirow{2}{*}{$\begin{array}{c}\text { REGIÃO DE } \\
\text { PLANEJA- } \\
\text { MENTO }\end{array}$} & \multirow{2}{*}{1960} & \multirow{2}{*}{1970} & \multirow{2}{*}{1980} & \multirow{2}{*}{1991} & \multicolumn{4}{|c|}{ TAXA DE CRESCIMENTO } \\
\hline & & & & & & $1960 / 70$ & 1970/80 & 1980/91 & $1960 / 91$ \\
\hline Patos de Minas .......... & $\mathrm{V}$ & 31471 & 42161 & 59896 & 83845 & 34,0 & 39,7 & 40,0 & 166,4 \\
\hline Patrocínio ............. & IV & - & - & 29520 & 45405 & 42,1 & 49,0 & 53,8 & 225,9 \\
\hline Pedro Leopoldo . & I & _- & _- & _- & 29042 & 49,1 & 59,4 & 51,4 & 259,9 \\
\hline Pirapora .... & VI & - & - & 31533 & 45492 & 37,6 & 66,3 & 44,3 & 230,3 \\
\hline Piui $\ldots \ldots \ldots \ldots \ldots$ & $\mathrm{V}$ & _ & - & _- & 20758 & 17,6 & 63,9 & 17,5 & 126,5 \\
\hline Poços de Caldas.......... & III & 32291 & 51783 & 81448 & 105205 & 60,4 & 57,3 & 29,2 & 225,8 \\
\hline Ponte Nova . & II & 22536 & 28609 & 34807 & 42136 & 26,9 & 21,7 & 21,0 & 87,0 \\
\hline Pouso Alegre ............. & III & - & 29208 & 50517 & 73923 & 54,9 & 73,0 & 46,3 & 292,1 \\
\hline Ribeirão das Neves . . . . . . & I & - & - & - & 34376 & 17,0 & 201,2 & 199,1 & 954,5 \\
\hline S. Sebastião do Paraíso ... & III & _- & _- & 28482 & 39859 & 30,7 & 50,7 & 39,9 & 161,1 \\
\hline Sabará ................ & I & - & - & 22883 & 27720 & 86,8 & 22,3 & 21,1 & 177,1 \\
\hline Santa Luzia . ............ & I & - & - & 24646 & 38410 & 73,6 & 88,4 & 55,8 & 410,1 \\
\hline Santa Rita do Sapucaí .... . & III & - & - & - & 20091 & 12,4 & 68,0 & 25,6 & 137,4 \\
\hline Santos Dumont ........... & II & 20414 & 27006 & 31053 & 36307 & 32,3 & 15,0 & 16,9 & 77,8 \\
\hline São João del Rey . & I & 34564 & 44991 & 53401 & 63685 & 29,8 & 18,7 & 19,2 & 84,2 \\
\hline São Lourenço . & III & - & - & 23047 & 29498 & 23,3 & 27,2 & 28,0 & 100,9 \\
\hline Sete Lagoas ..... & I & 36302 & 61001 & 94502 & 139975 & 68,0 & 54,9 & 48,1 & 285,6 \\
\hline Teófilo Otoni . . . . . . . . . . . & VIII & 41013 & 64718 & 83108 & 96516 & 57,8 & 28,4 & 16,1 & 135,3 \\
\hline Timóteo ...... & I & _ & 29921 & 40817 & 48231 & 51,1 & 36,4 & 18,2 & 143,6 \\
\hline Três Corações . . . . . . . . . . . & III & _- & 25666 & 36179 & 49134 & 46,6 & 41,0 & 35,8 & 180,8 \\
\hline Três Pontas ......... & III & - & - & 24225 & 33631 & 23,2 & 70,3 & 38,8 & 191,6 \\
\hline Ubá............ & II & 21767 & 28885 & 43080 & 52745 & 33,7 & 49,1 & 22,4 & 142,3 \\
\hline Uberaba ....... & IV & 72053 & 108259 & 180296 & 199011 & 50,2 & 66,5 & 10,4 & 176,2 \\
\hline Uberlândia. ......... & IV & 70719 & 110289 & 230400 & 355524 & 56,0 & 108,9 & 54,3 & 402,7 \\
\hline Unaí . & VI & _- & _- & 28148 & 40817 & 201,4 & 121,5 & 45,0 & 868,6 \\
\hline Varginha.... & III & 24944 & 36375 & 57448 & 82242 & 45,1 & 57,9 & 43,1 & 229,7 \\
\hline Várzea da Palma . . . . . . . . . & VI & _- & _- & _- & 22823 & 84,3 & 95,4 & 103,0 & 631,0 \\
\hline Vespasiano $\ldots \ldots \ldots \ldots$ & I & - & - & - & 29213 & 17,6 & 329,7 & 86,8 & 844,2 \\
\hline Viçosa ............... & II & - & - & 29198 & 40124 & 66,4 & 87,7 & 37,4 & 329,5 \\
\hline Visconde do Rio Branco ... & II & _- & _- & _- & 21040 & 13,4 & 25,7 & 19,4 & 70,2 \\
\hline
\end{tabular}

Quadro 12: Cidades com população superior a 20.000 habitantes nas datas dos recenseamentos gerais de 1960, 1970,1980,1991.

Chart 12: Cities with population of 20.000 or over in 1960, 1970, 1980, 1991. 


\section{CENTROS EMERGENTES E DINÂMICOS}

Dentro do quadro geral de relativa acomodação no crescimento das cidades mineiras evidenciado da década de 1980 para 1991, merecem destaque algumas cidades que mantiveram o vigor de suas taxas de crescimento, mostrando indicadores superiores desta década em relação à década anterior. São 15 cidades conforme dados do quadro 13 a seguir.

Como se observa são cidades que podem ser classificadas como de porte médio com totais populacionais que variam aproximadamente, entre 20 e 69 mil habitantes.

Algumas, como Patrocínio, Guaxupé, Várzea da Palma e Lagoa Santa vêm mostrando um ritmo notável de crescimento demográfico desde a década de 1960 as outras 11 cidades mostram um comportamento oscilante no período considerado.

A análise das causas geradoras destes comportamentos mereceriam estudos mais detalhados, caso a caso, o que foge ao objetivo imediato deste texto. Todavia podemos destacar as cidades de Ibirité e Lagoa Santa, como hipótese de exemplos de cidades localizadas na periferia imediata da Região Metropolitana de Belo Horizonte e que funcionam como alternativa de moradia para aqueles que por opção ou por expulsão já não conseguem manter residência no núcleo da Região Metropolitana de Belo Horizonte.

Se considerarmos a distribuição por regiões de planejamento verificamos que existe uma certa lógica na distribuição espacial em função do nível de desenvolvimento econômico regional.

Assim é que a Região I (Metalúrgica), Região II (Mata) e Região III (Sul) são sede para 03 (três cidades cada uma; e na Região IV (Triângulo) estão localizadas 02 (duas) destas cidades. Nas demais regiões, justamente as de menor desenvolvimento, só se localiza uma das cidades (Cartograma 2).

\section{CONCLUSÃO}

A população de Minas Gerais, seguindo uma tendência quase universal, vem se urbanizando em um ritmo acelerado, com uma taxa geométrica de crescimento anual da ordem de $4,9 \%$.

Este processo de urbanização vem se desenvolvendo desde a década de 60, tendo se tornado mais nítido a partir de 1970, quando o Estado passa a ter a maior parte de sua população residindo em cidades.

Nas três décadas estudadas, analisando em termos espaciais, esta urbanização ocorreu intensamente nas Regiões I, II, III, IV e V (Sul, Sudeste, Centro Oeste e Oeste do Estado), enquanto que as Regiões VI, VII e VIII, que compõe o Norte e Nordeste do Estado continuam a ser a porção menos urbanizada do Estado, sendo que a Região VII (Jequitinhonha) é a única que permanece com uma população urbana menor que a rural.

O reflexo desta urbanização, a nível de cidades, nos mostra uma excessiva concentração nos grandes centros:

\begin{tabular}{|c|c|c|c|c|c|c|c|c|c|}
\hline \multirow{2}{*}{ CIDADES } & \multirow{2}{*}{$\begin{array}{c}\text { REGIÃO DE } \\
\text { PLANEJA- } \\
\text { MENTO }\end{array}$} & \multirow{2}{*}{1960} & \multirow{2}{*}{1970} & \multirow{2}{*}{1980} & \multirow{2}{*}{1991} & \multicolumn{4}{|c|}{ TAXA DE CRESCIMENTO } \\
\hline & & & & & & $1960 / 70$ & $1970 / 80$ & 1980/91 & $1960 / 91$ \\
\hline Itajubá . & III & 31262 & 42477 & 53506 & 68856 & 35,9 & 26,0 & 28,7 & 120,2 \\
\hline Lavras ........ & III & 23793 & 35489 & 43545 & 60730 & 49,2 & 27,8 & 39,5 & 155,2 \\
\hline Patrocínio ........... & IV & - & - & 29520 & 45405 & 42,1 & 49,0 & 53,8 & 225,9 \\
\hline Nanuque $\ldots \ldots \ldots \ldots$ & VIII & - & 34565 & 34445 & 37095 & 91,2 & $-0,3$ & 7,7 & 105,2 \\
\hline Santos Dumont . & II & 20414 & 27006 & 31053 & 36307 & 32,3 & 15,0 & 16,9 & 77,8 \\
\hline Ouro Preto ............ & I & - & 24043 & 27821 & 35241 & 63,3 & 15,7 & 26,7 & 139,4 \\
\hline Guaxupé ............ & III & - & - & 23637 & 34368 & 22,1 & 36,5 & 45,4 & 142,6 \\
\hline Ibirité ... & I & - & - & - & 33313 & 23,4 & 214,5 & 327,5 & 1654,2 \\
\hline Frutal $\ldots \ldots \ldots \ldots \ldots$ & IV & - & - & 22955 & 31980 & 104,8 & 35,8 & 39,3 & 287,5 \\
\hline Bom Despacho ........ & $\mathrm{V}$ & - & - & 22941 & 29520 & 38,2 & 22,3 & 28,9 & 117,6 \\
\hline Além Paraíba .......... & II & - & 21743 & 23028 & 26202 & 18,1 & 5,9 & 13,8 & 42,4 \\
\hline Diamantina...$\ldots \ldots \ldots$ & VII & - & - & 20197 & 26074 & 24,0 & 14,2 & 29,1 & 83,0 \\
\hline Várzea da Palma . & VI & - & - & - & 22823 & 84,3 & 95,4 & 103,0 & 631,0 \\
\hline Lagoa Santa . . & I & - & - & - & 22797 & 18,5 & 53,7 & 66,2 & 202,7 \\
\hline Carangola $\ldots \ldots \ldots \ldots$ & II & - & - & - & 20216 & 27,7 & 4,7 & 27,1 & 69,9 \\
\hline
\end{tabular}

Chart 13: Cities with population of 20.000 and over, with increasing rate or growth (between 1980 and 1991). 


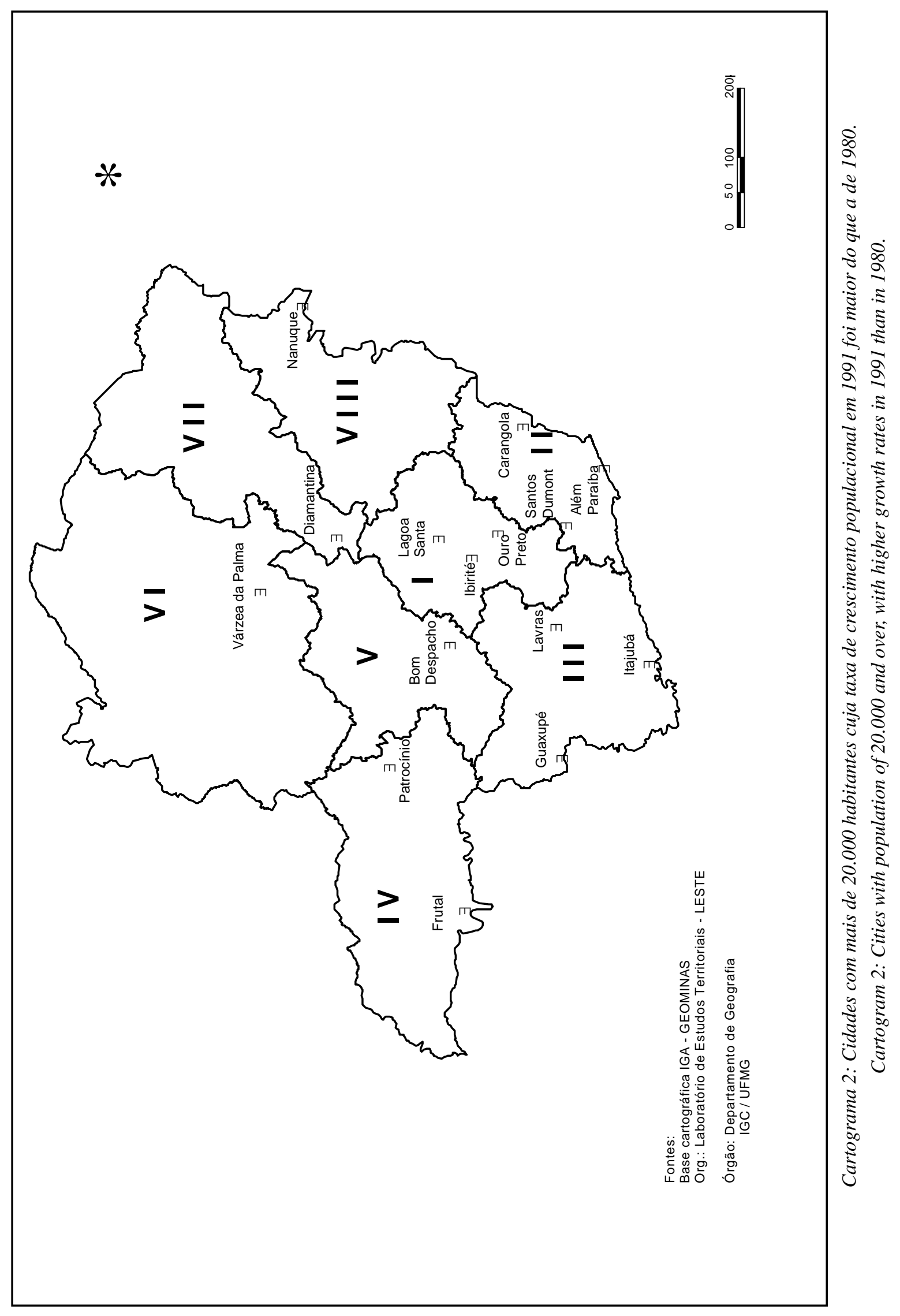


as cidades de mais de 100 mil habitantes concentraram cerca de $37,4 \%$ da população urbana de Minas Gerais, sendo que Belo Horizonte, isoladamente, corresponde a $15,2 \%$ (1991).

A população urbana se acha pulverizada em um grande números de pequenas e médias cidades. Os segmentos que mais cresceram, entre 1980 e 1991, foram os das cidades de 200 a 500 mil habitantes e de 20 a 50 mil habitantes, que foram responsáveis por $30,5 \%$ e $25,2 \%$ do crescimento total da população urbana mineira. Os aglomerados urbanos na faixa de 10 a 20 mil habitantes, também tiveram uma participação importante no incremento da população urbana com $17,5 \%$.

A Região VI aparece revitalizada, quando verifica-se o crescimento e a distribuição das cidades de mais de 20 mil habitantes: em 1970, tinha apenas um centro desse tamanho, em 1980, aparece com 6 cidades e em 1991, consolida-se com 9 cidades desse porte.

Estas e outras informações que o estudo fornece comprovam o caráter essencialmente dinâmico do processo de urbanização e a necessidade, cada dia mais presente, de seu acompanhamento e análise a nível de distribuição espacial e das próprias cidades.

O cartograma de localização regional dos centros ascendentes (de 10 a 20 mil habitantes) reforça esta idéia, pois demonstra algumas regiões, como a III por exemplo, com uma série de cidades deste tamanho, ou seja, apresentando um potencial urbano que não é muito perceptível numa análise estática da situação atual.

\section{BIBLIOGRAFIA}

ALEGRE, Marcos. Aspectos do fato urbano no Brasil; análise quantitativa pelo método cartográfico. s.1., Faculdade de Filosofia Ciências e Letras de Presidente Prudente, 1970.290 p. il.

BREMAEKER, François Eugéne Jean de. A evolução da urbanização brasileira em três décadas: 1940 - 1970. Revista Brasileira de Estatística, Rio de Janeiro, 37 (145): 47 - 80, jan./mar. 1976

CARVALHO, Aílton M. de, Evolução da urbanização mineira em duas décadas: 1960/1970 e 1970/1980. Ind. Conj. MG, Belo Horizonte, 7(3): 335-353, p. 335 - 353, junho de 1985.

IBGE, Rio de Janeiro. Censo demográfico de 1960 - Minas Gerais. Rio de Janeiro, s.d. (VII Recenseamento Geral do Brasil. Série Regional, v.1, t.9).

IBGE, Censo demográfico de Minas Gerais. Rio de Janeiro, 1973.3v. (VIII Recenseamento Geral, 1970. Série Regional, v.1, t.14).

IBGE, Sinopse preliminar do Censo demográfico de Minas Gerais. Rio de Janeiro, 1982. 214 p. (IX Recenseamento Geral do Brasil, 1980. V.2, t.1, n.9.).

IBGE, Censo demográfico de 1991 - Minas Gerais. Rio de Janeiro. p. 1 - 1037, n.18. 1991. 